\title{
Genotype-phenotype correlations among BRCA1 4153delA and 5382insC mutation carriers from Latvia
}

Grigorijs Plakhins ${ }^{1,2^{*}}$, Arvids Irmejs ${ }^{1,3}$, Andris Gardovskis ${ }^{1,3}$, Signe Subatniece ${ }^{1}$, Santa Rozite ${ }^{4}$, Marianna Bitina ${ }^{5}$, Guntars Keire ${ }^{6}$, Gunta Purkalne ${ }^{2}$, Uldis Teibe ${ }^{7}$, Genadijs Trofimovics ${ }^{1,3}$, Edvins Miklasevics ${ }^{1}$ and Janis Gardovskis ${ }^{1,3}$

\begin{abstract}
Background: Mutations in the high penetrance breast and ovarian cancer susceptibility gene BRCA1 account for a significant percentage of hereditary breast and ovarian cancer cases. Genotype-phenotype correlations of BRCA1 mutations located in different parts of the BRCA1 gene have been described previously; however, phenotypic differences of specific BRCA1 mutations have not yet been fully investigated. In our study, based on the analysis of a population-based series of unselected breast and ovarian cancer cases in Latvia, we show some aspects of the genotype-phenotype correlation among the BRCA1 c.4034delA (4153delA) and c.5266dupC (5382insC) founder mutation carriers.
\end{abstract}

Methods: We investigated the prevalence of the BRCA1 founder mutations c.4034delA and c.5266dupC in a population-based series of unselected breast $(n=2546)$ and ovarian $(n=795)$ cancer cases. Among the BRCA1 mutation carriers identified in this analysis we compared the overall survival, age at diagnosis and family histories of breast and ovarian cancers.

Results: We have found that the prevalence of breast and ovarian cancer cases (breast: ovarian cancer ratio) differs significantly among the carriers of the c.5266dupC and c.4034delA founder mutations $(\mathrm{OR}=2.98,95 \% \mathrm{Cl}=1.58$ to $5.62, \mathrm{P}<0.001)$. We have also found a difference in the prevalence of breast and ovarian cancer cases among the $1^{\text {st }}$ and $2^{\text {nd }}$ degree relatives of the c.4034delA and c.5266dupC mutation carriers. In addition, among the breast cancer cases the c.4034delA mutation has been associated with a later age of onset and worse clinical outcomes in comparison with the c.5266dupC mutation.

Conclusions: Our data suggest that the carriers of the c.4034delA and c.5266dupC founder mutations have different risks of breast and ovarian cancer development, different age of onset and prognosis of breast cancer.

\section{Background}

Breast cancer is the most prevalent malignancy and the leading cause of death from cancer among women in Latvia. Ovarian cancer appears less frequent; however, it remains a significant cause of cancer mortality in Latvia and worldwide. Hereditary cancer syndromes account for up to $5-10 \%$ of breast cancer cases and for up to 5$15 \%$ of ovarian cancer cases [1,2]. Germline mutations of the BRCA1 and BRCA2 genes represent the most

\footnotetext{
* Correspondence: grigorijs.plakhins@stradini.lv

${ }^{1}$ Hereditary Cancer Institute, Riga Stradins University, Dzirciema Street 16, Riga, LV-1007, Latvia

Full list of author information is available at the end of the article
}

significant and thus far the best characterized genetic risk factors for breast and ovarian cancer development [3]. More than 1000 distinct cancer-associated BRCA1 [MIM 113705] mutations have been already described; however, not all of them are equally pathogenic and most probably there is a different cancer risk associated with specific mutations [4]. In sporadic breast carcinoma, $B R C A 1$ is rarely mutated, although expression frequently is limited by DNA methylation-induced gene suppression. The BRCA1 protein has been implicated in different biological processes, including DNA repair, cell cycle control, transcriptional regulation, centrosome duplication and tumour suppressor function [5].

\section{Biomed Central}


Structural and functional changes of mutated proteins caused by different BRCA1 mutations are not identical and can lead to various phenotypes of cancers (genotype-phenotype correlations) [6]. Therefore, clinical presentations, outcome and response to treatment of tumours can differ significantly depending on the type of mutations. In the case of pathogenic BRCA1 mutations, it has been previously shown that mutations in exon 11 (nucleotides 2388-4185) of the BRCA1 gene are associated with almost equal breast and ovarian cancer incidence among mutation carriers (breast:ovarian cancer ratio) in comparison with mutations in other parts of the BRCA1 gene. On the other hand, mutations located 3' of nucleotide 4185 are usually associated with a higher risk of breast cancer development and with a relatively lower ovarian cancer risk [2,6]. Nevertheless, the genotype-phenotype correlations of the specific $B R C A 1$ founder mutations c.4034delA (also described as 4153delA (or 4154delA) in exon 11) and c.5266dupC (5382insC in exon 20) have not been fully investigated. In this article, we describe some aspects of genotypephenotype correlation among the c.4034delA and c.5266dupC mutation carriers identified in a populationbased screening in Latvia which was observed in the prevalence of breast and ovarian cancer cases among the mutation carriers and their $1^{\text {st }}$ and $2^{\text {nd }}$ degree relatives, in the age of onset and in the clinical outcomes of breast cancer.

\section{Methods}

The study population is comprised of 2546 unselected breast cancer patients and 795 unselected ovarian cancer patients who, during the period from 2000 to 2009, underwent genetic counselling and $B R C A 1$ founder mutation analysis at the Hereditary Cancer Outpatient Clinic of Pauls Stradins Clinical University Hospital in Riga, Latvia. Screening for the BRCA1 founder mutations c.4034delA and c.5266dupC was performed in different patient groups as follows: 1 ) in all the breast and ovarian cancer patients irrespective of family history (there were no exclusion criteria); 2) in patients with other cancer localizations and in healthy individuals when hereditary breast and ovarian cancer syndromes were suspected. The study was approved by the Ethical Committee of Riga Stradins University. All participants signed informed consent forms for participation in this study.

The information about the time of establishing breast cancer diagnosis, the TNM classification and the time and cause of death of cancer patients was confirmed in the Latvian Ministry of Health, the "Register of Patients Suffering from Particular Diseases, Patients with Cancer". The patients for the control group for breast cancer survival analysis were randomly selected from the breast cancer patients who were tested negative for the BRCA1 founder mutations, matched by tumour size, nodal status and age at diagnosis. Oestrogen receptor (ER), progesterone receptor (PR) and HER2/neu expression status was assessed using a standard immunohistochemical technique. The data on family histories were obtained from the database of the Hereditary Cancer Institute (in Riga Stradins University) as reported by probands. During genetic counselling the following data were collected using special questionnaires: the number of cancer cases among the $1^{\text {st }}-4^{\text {th }}$ degree relatives in the family with indication of cancer localization in the affected relatives, the age of onset of cancer disease and the age of death. The presence of BRCA1 founder mutations c.4034delA and c.5266dupC was determined as described elsewhere [7].

Statistical analysis was performed using EpiCalc 2000 version 1.02 and SPSS, version 19. We estimated the survival function with the Kaplan-Meier estimator and calculated cumulative incidences as one minus survival function. Differences in survival and cumulative incidence were compared with the Log Rank test. Adjusted Hazard Ratios (HR) were estimated with Cox proportional hazard regression. Association between cancer type and mutation was assessed with Odds Ratios (OR) and associated Mantel-Haenszel 95\% Confidence Intervals (CI). Comparison of two independent proportions was performed by Z-test.

\section{Results}

1. Different breast:ovarian cancer ratios among c.4034delA and c.5266dupC mutation carriers

Molecular analysis of BRCA1 founder mutations among 2546 unselected breast cancer patients has revealed the presence of mutations in $96(3.77 \%)$ cases, including 25 (0.98\%) c.4034delA mutations and 69 (2.70\%) c.5266dupC mutations. From 795 unselected ovarian cancer patients BRCA1 mutations were identified in 79 (9.90\%) cases, including 41 (5.10\%) c.4034delA and 38 (4.80\%) c.5266dupC mutations.

Among the 107 breast and ovarian cancer patients who were identified as the mutation c.5266dupC carriers, breast cancer cases accounted for $64 \%$; however, among the 76 breast and ovarian cancer patients c.4034delA mutation carriers breast cancer cases accounted only for $32 \%(\mathrm{OR}=2.98,95 \% \mathrm{CI}=1.58$ to $5.62, \mathrm{P}<0.001)$, which reflected the difference in the breast:ovarian cancer ratios among the carriers of these founder mutations. The difference in the breast:ovarian cancer relative risk associated with the c.5266dupC and c.4034delA founder mutations in this population-based series was calculated as $\mathrm{RR}=1.70(95 \% \mathrm{CI}=1.21$ to 2.39, $\mathrm{P}<0.001)$. 


\section{Age at diagnosis of breast and ovarian cancer}

In this population-based series the median age at diagnosis of breast cancer patients among the cases with no mutations was 60.21 (age range 21-95) years in comparison with 51.76 (age range 35-76) years among the c.4034delA mutation carriers and 46.51 (age range 2876) years among the c.5266dupC mutation carriers. The median age at diagnosis of ovarian cancer cases among the cases without mutations was 58.57 (age range 30-88) years in comparison with 53.21 (age range 28-73) years among the c.4034delA mutation carriers and 49.30 (age range 35-77) years among the c.5266dupC mutation carriers. The linear trends of age-related cumulative incidence of breast cancer cases are shown in Figure 1. We observed a significant difference in cumulative incidence of breast cancer among the c.5266dupC and c.4034delA mutation carriers $\left(\chi^{2}=4.39\right.$, with 1 degree of freedom, $\mathrm{P}=0.03)$. The difference in cumulative incidence of patients without mutations in comparison with the c.5266dupC ( $\chi^{2}=137.57$, with 1 degree of freedom, $\mathrm{P}<$ $0.001)$ and c.4034delA $\left(\chi^{2}=15.27\right.$, with 1 degree of freedom, $\mathrm{P}=\mathrm{P}<0.001)$ mutation carriers was also statistically significant. The difference in age at diagnosis of ovarian cancer among the c.4034delA and c.5266dupC mutation carriers and patients without mutations was not statistically significant (data not shown).

\section{Survival analysis of breast cancer patients}

The breast cancer survival analysis includes 25 mutation c.4034delA carriers, 68 mutation c.5266dupC carriers and 103 patients without mutations, with a median follow-up period of 103 months. There were 36 women who died from breast cancer (7 in the c.4034delA group, 11 in the c.5266dupC group and 18 in the

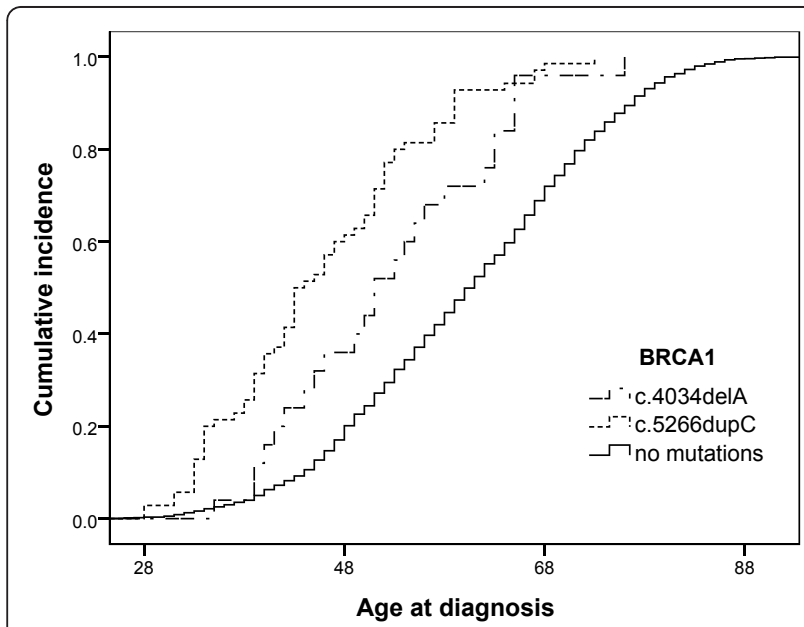

Figure 1 Age-related cumulative incidence of breast cancer cases among c.4034delA and c.5266dupC mutation carriers and patients without mutations. control group) and 13 women who died from causes other than breast cancer: 5 women died from ovarian cancer (1 in the c.4034delA group, 3 in the c.5266dupC group and 1 in the control group), 4 from cancers of other sites ( 1 in the c.4034delA group, 1 in the c.5266dupC group and 2 in the control group) and 4 deaths unrelated to cancer. The last 4 cases were included in survival analysis, but were counted as the end of the follow-up period and not as death events.

The mean estimated survival time during a 20 year follow-up period was calculated as 134 months (95\% CI $=92.58$ to 177.00$)$ in the c.4034delA group in comparison with 189 months in the c.5266dupC group (95\% CI $=166.75$ to 211.43 ) and 192 months in the control group (95\% CI $=175.54$ to 208.83 ). The cumulative survival plot is shown in Figure 2. Analysis of the KaplanMeier curves showed that the clinical outcome of breast cancer patients who were the c.4034delA mutation carriers was significantly worse in comparison with the c.5266dupC mutation carriers $\left(\chi^{2}=4.32\right.$, with 1 degree of freedom, $\mathrm{P}=0.038$ ) and with patients from the control group $\left(\chi^{2}=7.05\right.$, with 1 degree of freedom, $\mathrm{P}=$ $0.008)$. We did not observe any significant difference in tumour staging and lymph node status in both groups of mutation carriers (Table 1).

We also performed Cox regression analysis among breast cancer patients where cancer related mortality was used as the end point. The presence of the c.4034delA founder mutation remained an independent predictor of unfavourable prognosis in multivariable analysis among BRCA1 mutation carriers (Table 2). The presence of any $B R C A 1$ founder mutation was not

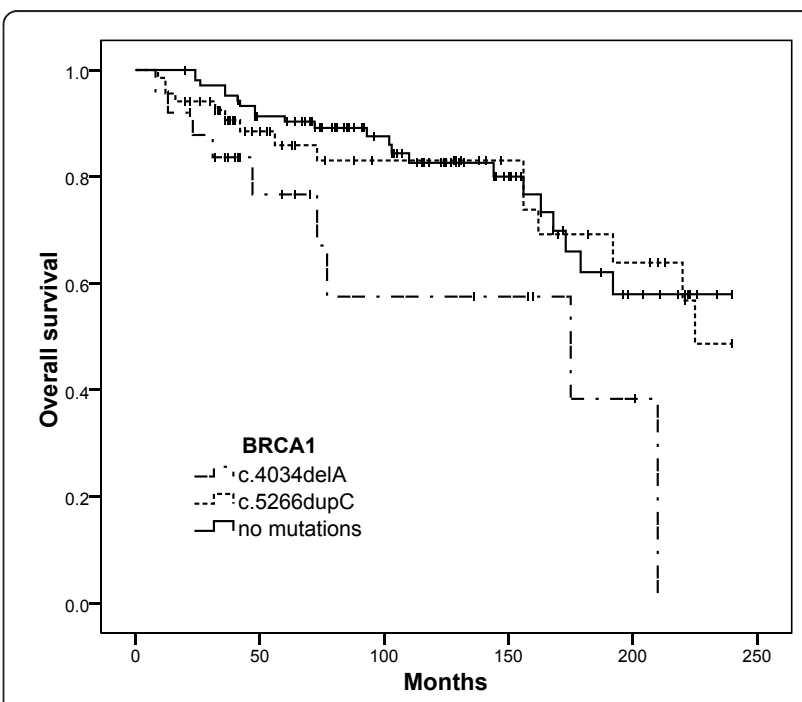

Figure 2 Overall survival of breast cancer patients - c.4034delA and c.5266dupC mutation carriers and patients without mutations. 
Table 1 Clinical characteristics of patients included in the survival analysis

\begin{tabular}{lccc}
\hline Variable & c.4034delA & c.5266dupC & Control \\
\hline N. of patients & 25 & 68 & 103 \\
Median age of onset (years) & 51.7 & 46.5 & 54.9 \\
T4 - n. (\%) & $5(20 \%)$ & $10(15 \%)$ & $7(7 \%)$ \\
T3 - n. (\%) & $1(4 \%)$ & $3(4 \%)$ & $13(13 \%)$ \\
T2 - n. (\%) & $14(56 \%)$ & $43(63 \%)$ & $63(61 \%)$ \\
T1 - n. (\%) & $5(20 \%)$ & $12(18 \%)$ & $20(19 \%)$ \\
Axillary node positive - n. (\%) & $14(56 \%)$ & $32(47 \%)$ & $44(43 \%)$ \\
ER/PR positive (\%) & $50 \%$ & $15 \%$ & $70 \%$ \\
HER2 positive (\%) & $22 \%$ & $11 \%$ & $70 \%$ \\
ER/PR/HER2 (Triple) negative (\%) & $50 \%$ & $79 \%$ & $24 \%$ \\
N. of patients dead from cancer during follow-up period & $9(36 \%)$ & $15(22 \%)$ & $21(20 \%)$ \\
\hline
\end{tabular}

significantly associated with unfavourable prognosis in multivariable analysis among all hereditary and sporadic breast cancer patients (Table 3). Hormone receptor status was not included in multivariate analysis, because it was available only for $52 \%$ of the patients. However, in univariable analysis hormone receptor negativity was significantly associated with unfavourable prognosis only among the patients without BRCA1 mutations $(\mathrm{HR}=$ $0.18,95 \% \mathrm{CI}=0.03$ to $0.98, \mathrm{P}=0.04$ ), whereas the impact of hormone receptor status on the prognosis of breast cancer among BRCA1 mutation carriers was not statistically significant $(\mathrm{HR}=1.09,95 \% \mathrm{CI}=0.21$ to 5.67, $\mathrm{P}=0.91)$.

4. Different prevalence of breast and ovarian cancer cases among relatives of c.4034delA and c.5266dupC mutation carriers

Hereditary cancer institute database contains information about 207 families of BRCA1 founder mutation carriers (including 79 families of c.4034delA and 128 families of c.5266dupC mutation carriers) who were

Table 2 Multivariable Cox-regression analysis of BRCA1 C.4034delA and C.5266dupC mutation carriers breast cancer patients

\begin{tabular}{|c|c|c|c|c|}
\hline Variable & $n$ & HR & $95 \% \mathrm{Cl}$ & P-value \\
\hline \multicolumn{5}{|l|}{ BRCA1 mutations: } \\
\hline c.4034delA & 25 & 2.76 & $1.13-6.70$ & 0.02 \\
\hline c.5266dupC & 68 & & & \\
\hline \multicolumn{5}{|l|}{ Tumor size: } \\
\hline$<5 \mathrm{~cm}$ & 74 & 0.36 & $0.15-0.86$ & 0.02 \\
\hline$>5 \mathrm{~cm}$ & 19 & & & \\
\hline \multicolumn{5}{|l|}{ Axillary node: } \\
\hline Negative & 44 & 0.34 & $0.13-0.89$ & 0.03 \\
\hline Positive & 49 & & & \\
\hline \multicolumn{5}{|l|}{ Age at diagnosis: } \\
\hline$<50$ & 51 & 1.53 & $0.65-3.61$ & 0.32 \\
\hline$>50$ & 42 & & & \\
\hline
\end{tabular}

identified during genetic screening in Latvia. Overall, the c.4034delA mutation carriers reported about cancer cases in their families more frequently in comparison with the c.5266dupC mutation carriers (the average amount of individuals ill with cancer in c.4034delA families was 2.9 individuals per family in comparison with 2.1 individuals per family reported in the c.5266dupC group, $\mathrm{P}=0.009$ ). The amount of "breast cancer families" with a history of only breast cancer cases and without ovarian cancer cases (at least two $1^{\text {st }}$ or $2^{\text {nd }}$ (related through a man) degree relatives) was higher among the c.5266dupC mutation carriers, whereas the amount of "breast and ovarian cancer families" with a history of ovarian cancer cases with or without breast cancer cases was higher among the carriers of the c.4034delA mutation. Probands, c.4034delA mutation carriers, have reported more frequently about multiple cases of any cancer ( 3 or 4 ) among the $1^{\text {st }}$ and $2^{\text {nd }}$ degree relatives in their families in comparison with the c.5266dupC mutation carriers (Table 4).

Due to the polygenic inheritance of breast and ovarian cancers, clustering of specific cancer localizations within

Table 3 Multivariable Cox-regression analysis of breast cancer patients

\begin{tabular}{lcccc}
\hline Variable & $\mathbf{n}$ & HR & $\mathbf{9 5 \% C l}$ & P-value \\
\hline $\begin{array}{l}\text { BRCA1 mutations: } \\
\quad \text { Mutation present }\end{array}$ & 93 & 1.10 & $0.81-1.48$ & 0.54 \\
$\quad \begin{array}{l}\text { Mutation absent } \\
\text { Tumor size: }\end{array}$ & 103 & & & \\
$\quad<5 \mathrm{~cm}$ & 157 & 0.68 & $0.49-0.94$ & 0.02 \\
$\quad>5 \mathrm{~cm}$ & 39 & & & \\
Axillary node: & & & & \\
$\quad \begin{array}{l}\text { Negative } \\
\quad \text { Positive }\end{array}$ & 103 & 0.34 & $0.37-0.77$ & $<0.01$ \\
Age at diagnosis: & 93 & & & \\
$\quad<50$ & & & & 0.55 \\
$\quad>50$ & 89 & 1.19 & $0.66-2.17$ & \\
\hline
\end{tabular}


Table 4 Family histories of BRCA1 c.4034delA and c.5266dupC mutations carriers

\begin{tabular}{|c|c|c|c|c|}
\hline Types of family histories & c.4034delA & c.5266dupC & $95 \% \mathrm{Cl}$ & P-value \\
\hline No data about cancer cases among $1^{\text {st }}$ and $2^{\text {nd }}$ degree relatives & $9 \%(7)$ & $22 \%(28)$ & $2.44-23.56$ & 0.02 \\
\hline At least 3 cancer cases among $1^{\text {st }}$ and $2^{\text {nd }}$ degree relatives (including breast and ovarian) & $48 \%(38)$ & $29 \%(37)$ & 4.46-33.54 & 0.008 \\
\hline At least 3 cancer cases among $1^{\text {st }}$ and $2^{\text {nd }}$ degree relatives (without breast and ovarian) & $14 \%(11)$ & $6 \%(8)$ & $-2.05-17.45$ & 0.08 \\
\hline At least 4 cancer cases among $1^{\text {st }}$ and $2^{\text {nd }}$ degree relatives (including breast and ovarian) & $30 \%(24)$ & $15 \%(19)$ & 2.14-27.86 & 0.01 \\
\hline Breast cancer families ${ }^{1}$ & $9 \%(7)$ & $24 \%(31)$ & $4.25-25.75$ & 0.01 \\
\hline Breast and ovarian cancer families ${ }^{2}$ & $34 \%(27)$ & $18 \%(23)$ & 2.61-29.39 & 0.01 \\
\hline Total amount of families included & 79 & 128 & & \\
\hline
\end{tabular}

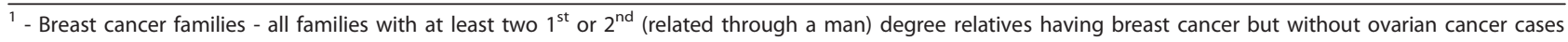
in family.

${ }^{2}$ - Breast and ovarian cancer families - all families with at least two $1^{\text {st }}$ or $2^{\text {nd }}$ (related through a man) degree relatives having breast or ovarian cancers.

families can be considered an important factor for unspecific bias of results obtained by analysing family histories. To overcome this problem we also investigated the prevalence of breast, ovarian and other cancer localizations among all the $1^{\text {st }}$ and $2^{\text {nd }}$ degree relatives of the carriers of both BRCA1 founder mutations irrespective of family composition. The prevalence of different cancer localizations among all the $1^{\text {st }}$ and $2^{\text {nd }}$ degree relatives of the c.4034delA and c.5266dupC mutation carriers is shown in Table 5.

\section{Discussion}

In this study we investigated the prevalence of the most common BRCA1 founder mutations in a populationbased series of breast and ovarian cancer cases in Latvia. Over the past several years, genetic counselling and screening of BRCA1 founder mutations have covered more than $50 \%$ of all breast and ovarian cancer cases registered in Latvia each year, thus providing information about the prevalence of hereditary cancer syndromes and BRCA1 founder mutations in unselected groups of breast and ovarian cancer patients. The fact that we investigated the prevalence of only 2 specific founder mutations is the major limitation of our study; however, according to the already published data, these
2 founder mutations account for more than $80 \%$ of all the BRCA1 mutations that were found among the cancer patients in Latvia $[8,9]$. Several population-based studies performed in neighbour countries of Latvia (Lithuania, Belarus and Poland) have demonstrated that 3 founder mutations - c.4034delA, c.5266dupC and c. $181 \mathrm{~T}>\mathrm{G}(300 \mathrm{~T} / \mathrm{G})$ - are the most widespread BRCA1 founder mutations in the southern Baltic region [10-14]. Previous studies in Latvia have shown that the c.181T/G mutation accounts for only $6-10 \%$ of the identified BRCA1 mutations when genetic analysis had been performed in selected early-onset breast and ovarian cancers patients [8] or in specific Latvian regions [9]. Nevertheless, according to our estimation the prevalence of the c.181T/G founder mutation among unselected breast and ovarian cancer patients in Latvia is much lower. The exact prevalence of BRCA1 founder mutations in Latvia is difficult to investigate due to relatively high heterogeneity of the Latvian population; however, in the analysis of a population screening of hereditary cancer syndromes in the Valka district of Latvia, the prevalence of BRCA1 founder mutations in the Latvian population was estimated at approximately $0.05 \%$ [7].

In our study we also found some phenotypic variations of hereditary breast and ovarian cancer syndromes

Table 5 Prevalence of different cancer localizations among $1^{\text {st }}$ and $2^{\text {nd }}$ degree relatives of probands who were BRCA1 c.4034delA and c.5266dupC mutation carriers (in \% of all the reported cancer cases in each group)

\begin{tabular}{lcccc}
\hline Cancer site & c.4034delA & c.5266dupC & 95\% Cl & P-value \\
\hline Breast & $19.0 \%$ & $34.0 \%$ & 7.16 to 22.84 & 0.0002 \\
Ovary & $19.0 \%$ & $8.0 \%$ & 4.66 to 17.34 & 0.0003 \\
Other gynaecological cancers* & $16.0 \%$ & $8.0 \%$ & 1.94 to 14.06 & 0.006 \\
Colon and rectum & $2.6 \%$ & $3.1 \%$ & -2.75 to 3.75 & n.s \\
Pancreas & $1.3 \%$ & $1.3 \%$ & -2.35 to 2.35 & n.s \\
Prostate & $1.7 \%$ & $2.4 \%$ & -2.12 to 3.52 & n.s \\
Stomach & $11.3 \%$ & $9.6 \%$ & -4.00 to 7.40 & n.s \\
Lung & $6.5 \%$ & $2.7 \%$ & -0.28 to 7.88 & \\
Total amount of relatives reported as having cancer & 230 & 290 & & \\
\hline
\end{tabular}

* - Other gynaecological cancers include ovarian, uterine and cervical cancer cases when exact localization of cancer was unknown. n.s. - non-significant 
among the c.4034delA and c.5266dupC mutation carriers. First of all, we observed a significant difference in the prevalence of c.4034delA and c.5266dupC mutation carriers among the breast and ovarian cancer patients. The breast:ovarian cancer ratio was higher among the c.5266dupC mutation carriers and lower among the c.4034delA mutation carriers. Despite the fact that some previous reports have shown an almost equal breast: ovarian cancer ratio among the c.4034delA and c.5266dupC mutation carriers in Latvia, in these studies genetic analysis was performed in relatively small hospital-based cohorts that can explain these discrepancies [8,9]. BRCA1 c.4034delA was initially described as a low penetrance breast cancer mutation [15]. Several other reports have demonstrated an increased prevalence of ovarian cancer cases among the c.4034delA mutation carriers [12-14]. In the analysis of hospital-based series of breast and ovarian cancer cases in Belarus the breast: ovarian cancer ratio among the c.4034delA and c.5266dupC mutation carriers was similar to the breast: ovarian cancer ratio obtained in our population-based series [13].

Several studies have shown some other phenotypic variations besides breast:ovarian cancer ratios associated with mutations, located in different parts of the BRCA1 gene. Satagopan et al found that the estimated lifetime risk of ovarian cancer development were two times as high for the c.68_69delAG (185delAG) mutation (66\%) than for the c.5266dupC mutation (29\%) [16]. Al-Mulla et al showed that age-related expressivity and penetrance of breast and ovarian cancers depended on the mutation position in the BRCA1 gene and differed among the carriers of various mutations located in exons 2, 11 and 13 [17].

The genotype-phenotype correlation effect among the c.4034delA and c.5266dupC mutation carriers observed in our study had two other interesting features. The median age of onset of breast and ovarian cancers among the c.5266dupC mutation carriers was smaller than among the c.4034delA mutation carriers. A similar trend in the age of onset of breast cancer cases among the c.4034delA and c.5266dupC mutation carriers was previously shown in a hospital-based series of Belarusian breast cancer patients; however, in this report the median age at diagnosis of breast cancer was lower than in our population-based series (48 years in patients without mutations, 43 years in c.5266dupC carriers and 44 years in c.4034delA carriers) [13].

Despite many conflicting reports about the prognostic significance of $B R C A 1$ mutations in breast cancer patients (where patients with different mutations were usually combined in common groups) [18-20], the influence of individual $B R C A 1$ mutations on the clinical outcomes of breast cancer patients has not been fully investigated. In our study we observed a worse clinical outcome for the c.4034delA mutation carriers in comparison with the c.5266dupC mutation carriers and the sporadic breast cancer patients. To some extent, this observation can be attributed to the way a part of the patients were referred to genetic counselling. In many cases, patients were counselled when they were admitted to hospital due to a recurrence of the cancer process or appearance of cancers in other sites. Among the c.5266dupC mutation carriers, more than $20 \%$ of breast cancer patients were diagnosed with contralateral breast cancer, when the primary site had been successfully treated in some cases more than 20 years ago. Among the carriers of the c.4034delA mutation such cases were observed less frequently (there was only one case with a disease-free period of 10 years until contralateral breast cancer was diagnosed); however, there was a substantial amount of patients with a progression of primary breast cancer processes which dramatically reduced survival in many cases. In spite of this fact, worse overall survival among the c.4034delA mutation carriers was not associated with an advanced stage at diagnosis. The amount of cases with locally advanced and node positives breast cancers did not differ significantly among all groups of patients included in the survival analysis. Furthermore, the multivariable analysis has shown that the presence of the c.4034delA mutation remained an independent predictive factor. On the other hand, improved survival among the c.5266dupC mutation carriers could not be attributed to prophylactic surgery or increased surveillance strategies. Indeed, these options have become available for the breast cancer patients with $B R C A 1$ mutations in Latvia just recently which might explain a relatively high amount of contralateral breast cancer cases among the carriers of both BRCA1 founder mutations.

Taken together, all the described above features show several aspects of genotype-phenotype correlation among the carriers of 2 specific BRCA1 founder mutations. Based on these data we can suggest that the carriers of the c.4034delA and c.5266dupC founder mutations have different risks of breast and ovarian cancer development, different age of onset and prognosis of breast cancer. The evaluation of the exact risk of specific genetic alterations in breast and ovarian susceptibility genes and possible synergistic effects between them can lead to a more precise prediction of the individual risk of developing specific cancers in hereditary breast and ovarian cancer patients. According to the suggestions of Mavaddat et al further decision about cancer surveillance and risk reducing strategies should take into account the individual risk differences based on the evaluation of the status of different genetic susceptibility factors [3]. For example, due to the genotype-phenotype 
correlation effect, carriers of the c.4034delA mutation have a more significant predisposition to ovarian cancer than the c.5266dupC mutation carriers. This can suggest a much stronger indication of risk-reducing salpingooophorectomy among the carriers of this founder mutation. Although the c.5266dupC founder mutation in this study was associated with better prognosis, the risk of breast cancer among asymptomatic mutation carriers as well as the risk of contralateral breast cancer among breast cancer patients, carriers of this founder mutation, remains high. This indicates the necessity of intensive surveillance strategies with a recommendation of riskreducing bilateral mastectomy for the carriers of this mutation. Several studies have shown that risk-reducing bilateral mastectomy reduces the risk of breast cancer among BRCA1 mutation carriers by approximately $90 \%$ and additional risk-reducing bilateral salpingo-oophorectomy improves this parameter by only $5 \%$ to a total of 95\% [21,22]. These data suggest that for carriers of the c.5266dupC mutation risk-reducing bilateral mastectomy without salpingo-oophorectomy can be sufficient riskreducing option, especially for women of childbearing age.

Despite their approved effectiveness, most cancer preventive strategies frequently reduce the quality of life of patients and are usually associated with a unique set of social, emotional and sexual factors for BRCA1 mutation carriers and their family members which can influence the decision making processes in many cases [23,24]. This issue indicates the importance of further clinical studies to evaluate the significance of different cancer prevention options among the carriers of specific genetic alterations in BRCA1 and other breast and ovarian cancer susceptibility genes.

\section{Conclusions}

In a population-based series of unselected breast and ovarian cancer cases in Latvia, the prevalence of breast cancer cases among the c.5266dupC mutation carriers was significantly higher in comparison with the c.4034delA mutation carriers, whereas the prevalence of ovarian cancer cases was almost similar. Among the c.4034delA mutation carriers, breast cancers were diagnosed at a later age and had worse clinical outcomes in comparison with the c.5266dupC mutation carriers. Based on our data we can suggest that carriers of the c.4034delA and c.5266dupC founder mutations have different risks of breast and ovarian cancer development, different age of onset and prognosis of breast cancer.

\section{Acknowledgements}

The study was supported by the National Research Programme "Development of new preventive, treatment, diagnostics means and practices and biomedicine technologies for improvement of public health (2010-2013)"

\section{Author details}

${ }^{1}$ Hereditary Cancer Institute, Riga Stradins University, Dzirciema Street 16, Riga, LV-1007, Latvia. ${ }^{2}$ Oncology Clinic, Pauls Stradins Clinical University Hospital, Pilsonu Street 13, Riga, LV-1002, Latvia. ${ }^{3}$ Surgery Clinic, Pauls Stradins Clinical University Hospital, Pilsonu Street 13, Riga, LV-1002, Latvia. ${ }^{4}$ The Centre of Health Economics, Ministry of Health of the Republic of Latvia, Duntes Street 12/22, Riga, LV-1005, Latvia. ${ }^{5}$ Department of Oncology, Daugavpils Regional Hospital, Vasarnicu Street 20, Daugavpils, LV-5417, Latvia. ${ }^{6}$ Oncology Clinic, Liepaja Piejuras Hospital, Jurmalas Street 2, Liepaja, LV-3401, Latvia. ${ }^{7}$ Department of Physics, Riga Stradins University, Dzirciema Street 16, Riga, LV-1007, Latvia.

\section{Authors' contributions}

GP conceived, designed and coordinated the study, performed statistical analysis and drafted the manuscript. Al participated in the analysis of data, coordinated the study and helped to draft the manuscript. AG, SS, SR, MB, GK participated in the analysis of data and provided study material. GP, GT helped to draft the manuscript. UT supervised the statistical analysis. EM performed the molecular examinations, participated in the analysis of data and helped to draft the manuscript. JG coordinated the study and helped to draft the manuscript. All authors read and approved the final manuscript.

\section{Competing interests}

The authors declare that they have no competing interests.

Received: 6 March 2011 Accepted: 27 October 2011

Published: 27 October 2011

\section{References}

1. Tan DS, Marchiò C, Reis-Filho JS: Hereditary breast cancer: from molecular pathology to tailored therapies. J Clin Pathol 2008, 61(10):1073-1082.

2. Ramus SJ, Gayther SA: The Contribution of BRCA1 and BRCA2 to Ovarian Cancer. Mol Oncol 2009, 3(2):138-150.

3. Mavaddat N, Antoniou AC, Easton DF, Garcia-Closas M: Genetic susceptibility to breast cancer. Mol Oncol 2010, 4(3):174-191.

4. Hohenstein P, Fodde R: Of mice and (wo)men: genotype-phenotype correlations in BRCA1. Hum Mol Genet 2003, 12(Spec No 2):R271-7.

5. Wu W, Koike A, Takeshita T, Ohta T: The ubiquitin E3 ligase activity of BRCA1 and its biological functions. Cell Division 2008, 3:1.

6. Thompson D, Easton D, Breast Cancer Linkage Consortium: Variation in BRCA1 cancer risks by mutation position. Cancer Epidemiol Biomarkers Prev 2002, $11(4): 329-336$.

7. Vanags A, Strumfa I, Gardovskis A, et al: Population screening for hereditary and familial cancer syndromes in Valka district of Latvia. Hered Cancer Clin Pract 2010, 8(1):8.

8. Tikhomirova L, Sinicka O, Smite D, Eglitis J, Hodgson SV, Stengrevics A: High prevalence of two BRCA1 mutations, 4154delA and 5382insC, in Latvia. Familial Cancer 2005, 4(2):77-84.

9. Gardovskis A, Irmejs A, Miklasevics E, et al: Clinical, Molecular and Geographical Features of Hereditary Breast/Ovarian Cancer in Latvia. Hered Cancer Clin Pract 2005, 3(2):71-76.

10. Gronwald J, Elsakov P, Górski B, Lubiński J: High incidence of 4153 delA $B R C A 1$ gene mutations in Lithuanian breast- and breast-ovarian cancer families. Breast Cancer Res Treat 2005, 94(2):111-113.

11. Gorski B, Byrski T, Huzarski $T$, et al: Founder mutations in the BRCA1 gene in Polish families with breast-ovarian cancer. Am J Hum Genet 2000, 66:1963-1968.

12. Elsakov $P$, Kurtinaitis J, Petraitis $S$, et al: The contribution of founder mutations in BRCA1 to breast and ovarian cancer in Lithuania. Clin Genet 2010, 78(4):373-376.

13. Bogdanova NV, Antonenkova NN, Rogov YI, Karstens JH, Hillemanns P, Dörk T: High frequency and allele-specific differences of BRCA1 founder mutations in breast cancer and ovarian cancer patients from Belarus. Clin Genet 2010, 78(4):364-372.

14. Menkiszak J, Gronwald J, Górski B, et al: Hereditary ovarian cancer in Poland. Int J Cancer 2003, 106(6):942-945. 
15. Gorski B, Menkiszak J, Gronwald J, Lubinski J, Narod SA: A protein truncating $B R C A 1$ allele with a low penetrance of breast cancer. J Med Genet 2004, 41(12):e130.

16. Satagopan JM, Boyd J, Kauff ND, et al: Ovarian Cancer Risk in Ashkenazi Jewish Carriers of BRCA1 and BRCA2 Mutations. Clin Cancer Res 2002, 8(12):3776-3781.

17. Al-Mulla F, Bland JM, Serratt D, Miller J, Chu C, Taylor GT: Age-dependent penetrance of different germline mutations in the BRCA1 gene. J Clin Pathol 2009, 62(4):350-356.

18. Cortesi L, Masini C, Cirilli C, et al: Favourable ten-year overall survival in a Caucasian population with high probability of hereditary breast cancer. BMC Cancer 2010, 10:90.

19. Robson ME, Chappuis PO, Satagopan J, et al: A combined analysis of outcome following breast cancer: differences in survival based on BRCA1/BRCA2 mutation status and administration of adjuvant treatment. Breast Cancer Res 2004, 6(1):R8-R17.

20. Rennert G, Bisland-Naggan S, Barnett-Griness $O$, et al: Clinical Outcomes of Breast Cancer in Carriers of BRCA1 and BRCA2 Mutations. N Engl J Med 2007, 357(2):115-123.

21. Rebbeck TR, Friebel T, Lynch HT: Bilateral Prophylactic Mastectomy Reduces Breast Cancer Risk in BRCA1 and BRCA2 Mutation Carriers: The PROSE Study Group. J Clin Oncol 2004, 22(6):1055-1062.

22. Hartmann LC, Sellers TA, Schaid DJ: Efficacy of bilateral prophylactic mastectomy in BRCA1 and BRCA2 gene mutation carriers. J Natl Cancer Inst 2001, 93(21):1633-1637.

23. Matloff ET, Barnett RE, Bober SL: Unraveling the next chapter: sexual development, body image, and sexual functioning in female $B R C A$ carriers. Cancer J 2009, 15(1):15-18.

24. Shulman LP: Hereditary Breast and Ovarian Cancer (HBOC): Clinical Features and Counseling for BRCA1 and BRCA2, Lynch Syndrome, Cowden Syndrome, and Li-Fraumeni Syndrome. Obstet Gynecol Clin North Am 2010, 37(1):109-133.

\section{Pre-publication history}

The pre-publication history for this paper can be accessed here: http://www.biomedcentral.com/1471-2350/12/147/prepub

doi:10.1186/1471-2350-12-147

Cite this article as: Plakhins et al:: Genotype-phenotype correlations among BRCA1 4153delA and 5382insC mutation carriers from Latvia. BMC Medical Genetics 2011 12:147.

\section{Submit your next manuscript to BioMed Central and take full advantage of:}

- Convenient online submission

- Thorough peer review

- No space constraints or color figure charges

- Immediate publication on acceptance

- Inclusion in PubMed, CAS, Scopus and Google Scholar

- Research which is freely available for redistribution

Submit your manuscript at www.biomedcentral.com/submit
Biomed Central 